\title{
Self-neglect of Spinal Injured Patients
}

\author{
A. D. Macleod, MB, ChB, MRANZCP \\ Visiting Psychiatrist, Spinal Injuries Unit, Burwood Hospital, Christchurch, New \\ Zealand.
}

\begin{abstract}
Summary
Self-neglect is a recognised, but poorly emphasised, complication of spinal cord injury, with a prevalence in this study of $9^{\circ}$ o of a consecutive sample of 400 patients. Self-neglect may be the presenting symptom of problems related to adjustment to disability, a major depressive disorder (DSM III criteria), or a clear and rational wish to die (existential self-neglect). Management is discussed, emphasising the importance of respecting spinal injured patients' autonomy.
\end{abstract}

Key words: Spinal cord injuries; Self-neglect; Depressive illness.

Self-neglect is a problem commonly encountered in the management of spinal injured patients (Judd and Burrows, 1986). In this article, the term selfneglect encompasses self-injurious behaviour (Schroeder et al.), overt selfdestructive and non-compliant behaviour, and covert or passive behaviour resulting in physical complications. There is a multitude of references to such behaviour in the literature. These include the rejection of necessary surgical procedures (Nagler, 1950), a compulsive and self-destructive need for polysurgery (Seymour and Comarr, 1956), a proneness to self-destructive behaviour (Hopkins, 1971), the refusal to eat (Gallagher et al., 1982), inattention to skin care (Nyquist and Bors, 1967; Wilcox and Stauffer, 1972; Kerr and Thompson, 1972; Steward, 1977-78), the avoidance of, or difficulties with, bladder care (Stewart 1977-78; Gallagher et al., 1982), the neglect of self-care (Hohmann, 1975), mutilative self-biting (Dahlin, et al., 1985), the reluctance to participate in rehabilitation (Nagler, 1950; Arnott, 1984), lack of cooperation with staff (Petrus and Balaban, 1953; Gallagher et al., 1982; Pinkerton and Griffin, 1983), and the reluctance of patients to return to specialist care despite deteriorating health (Bromley, 1984).

Treischman, 1980, stressed the importance of self-care of spinal injured patients by including, as one of the three categories of function relating to successful life post-spinal injury, the prevention of medical complications by 
self-care or by influencing the environment in such a manner as to ensure that appropriate care is received.

Alcohol abuse by spinal injured patients is a major concern (Geisler et al., 1983). Bedbrook (1985) states alcohol abuse is encountered in over $50 \%$ of people prior to spinal cord trauma, and Petrus and Balaban, 1953; Nyquist and Bors, 1967; Wilcox and Stauffer, 1972, indicate an increasing incidence of alcohol and drug related problems, including neglect of care and overdosage, post-spinal injury.

Judd and Burrows, 1986, comment that self-neglect may be a consequence of unrecognised and untreated depressive illness. Depression following acute spinal injury is reviewed by Judd et al., 1986. Treischman, 1980, Malec and Neimeyer, 1981 and Judd et al., 1986, conclude depression adversely influences both short and long term rehabilitation. Malec and Neimeyer, 1981, conclude that emotional factors, such as distress and/or depression, adversely affect the learning and performance of self-care.

There is a higher rate of suicide of spinal injured patients than in the general population (Hopkins, 1971; Nyquist and Bors, 1967; Wilcox and Stauffer, 1972; Pinkerton and Griffin, 1983; Geisler et al., 1983, Judd and Burrows, 1986). In addition to these cases of overt self-destruction, Nyquist and Bors (1967) suggest that some undetermined or accidental deaths may well have been hastened by self-neglectful behaviour. Pinkerton and Griffin, 1983, describe such a case. Fifty per cent of patients with spinal cord injury describe suicidal thoughts (Pinkerton and Griffin, 1983), but relatively few actually attempt suicide.

The literature suggests that self-neglect is a frequently observed occurrence in spinal injured patients, and an aetiological factor in some of the medical complications of spinal cord injury. This article considers the symptom of selfneglect with respect to diagnosis and management of the underlying psychiatric state (Table).

\section{Method}

The Burwood Spinal Injuries Unit consists of 30 beds in conjunction with 10 Hostel beds and 4 Self-Care beds. It serves a catchment population of 1.8

Table

\begin{tabular}{|c|c|c|c|c|c|c|}
\hline & \multicolumn{2}{|c|}{$\begin{array}{l}\text { Adjustment to } \\
\text { disability }\end{array}$} & \multicolumn{2}{|c|}{$\begin{array}{c}\text { Major } \\
\text { depressive episode }\end{array}$} & \multicolumn{2}{|l|}{$\begin{array}{c}\text { Existential } \\
\text { self-neglect }\end{array}$} \\
\hline Number of patients & \multicolumn{2}{|l|}{21} & \multicolumn{2}{|l|}{9} & \multicolumn{2}{|l|}{6} \\
\hline Mean age & \multicolumn{2}{|c|}{28.4 years } & \multicolumn{2}{|c|}{59.8 years } & \multicolumn{2}{|l|}{38.5 years } \\
\hline Mean time since injury & \multicolumn{2}{|c|}{3.6 years } & \multicolumn{2}{|c|}{3.4 years } & \multicolumn{2}{|l|}{8.6 years } \\
\hline \multirow{2}{*}{ Level of lesion } & Paraplegia & 18 & Paraplegia & 8 & Paraplegia & \\
\hline & Tetraplegia & 3 & Tetraplegia & 1 & Tetraplegia & \\
\hline \multirow[t]{3}{*}{ Marital status } & Single & 14 & Single & 0 & Single & 3 \\
\hline & Divorced & 2 & Divorced & 1 & Divorced & 1 \\
\hline & Married & 5 & Married & 8 & Married & 2 \\
\hline \multirow[t]{2}{*}{ Sex } & Male & 18 & Male & 6 & Male & \\
\hline & Female & 3 & Female & 3 & Female & 2 \\
\hline \multirow{2}{*}{$\begin{array}{l}\text { Affective tone } \\
\text { Behavioural expression } \\
\text { of affect }\end{array}$} & \multicolumn{2}{|c|}{ Anger/Indifference } & \multicolumn{2}{|c|}{ Pervasive lowering } & \multicolumn{2}{|l|}{ Positive } \\
\hline & \multicolumn{2}{|c|}{ Acting Out/Withdrawal } & \multicolumn{2}{|c|}{$\begin{array}{c}\text { of mood } \\
\text { Negativism }\end{array}$} & \multicolumn{2}{|l|}{ Appropriate } \\
\hline
\end{tabular}


million, and a catchment area of approximately 200,000 square kilometers. In 1985-86 the Unit received 81 acute admissions and reviewed, either on an inpatient or outpatient basis, 319 spinal injured patients. A Consultation Liaison Psychiatric Service to the Spinal Injuries Unit was commenced in 1985. Each patient is routinely assessed by a social worker, and referral to the psychiatrist is made only if the Unit's medical or social work staff request an opinion. During $1985-86,67(16.7 \%)$ of these patients were psychiatrically examined.

\section{Results}

Thirty six $(53.7 \%$ of the psychiatric referrals, $9 \%$ of the total number of spinal injured patients) exhibited self-neglect (Table). The most frequently enacted behaviour was non-cooperation with the paramedical staff, followed by refusal to accept medication or treatment, flagrant misuse of medication, inattention to skin care, mismanagement of urinary catheter, not regulating fluid intake, and alcohol and/or drug related problems. Generally more than one such behaviour was found to be a problem at referral. From this grouping of 36 patients, three diagnostic clusters were clinically apparent. Twenty one $(58 \%)$ were experiencing ongoing and major problems relating to their adjustment to disability, $9(25 \%)$ patients displayed the signs and symptoms of a major depressive episode (DSM III), and $6(16.6 \%)$ patients expressed a calm and considered request that medical treatment be withdrawn. Self-neglect was a symptom of an adjustment process, a major depressive episode or an 'existential suicide'.

\section{Adjustment self-neglect}

The majority of these patients were male, paraplegic, their mean age 28.4 years and the mean time lapse since injury was 3.6 years. Clinically these patients presented with either rebellious, overtly angry and hostile self-neglect or indifferent, passively withdrawn behaviour which was covertly self-destructive. The behaviour repertoire was erratic and fluctuated with their waves of grief, the self-neglect not being necessarily consistent or persistent. Regressed, infantile, and self-centred (narcissistic) behaviour were apparent. Sad mood, irritability and a fragile self-esteem (Nemiah, 1957) were evident. The physiological symptoms of a major depressive episode were absent. Denial of the consequences and prognosis of the injury had assumed maladaptive proportions and was expressed in actions (or inaction) rather than in words. The post-injury moratorium (Steward, 1977-78) was pathologically extended, the grief and adjustment processes having been arrested. The acute spinal injured patient is totally dependent on staff-adjustment to disability involves the gradual regaining and mastering of the art of living by reclaiming autonomy. The rebellious and 'adolescent' phase of this evolution may be expressed by selfneglect and the reluctance to acknowledge self-responsibility. This phase, though expected and necessary, may be aetiologically involved in the creation of long-term medical complications, particularly if the phase is prolonged.

The management of adjustment self-neglect involves supportive psychotherapeutic interventions (counselling) in combination with therapeutic patience (Steward 1977-78). An empathic therapist can assist the clarification of the 
intrapersonal and interpersonal conflicts, the catharsis of grief, and foster education and instruction regarding adequate self-care. Factors relating to the losses caused by the injury, the patient's personality, intelligence and pre-injury psychological conflicts, all require consideration, as do the staff-patient interactions. The core psychological conflict is the loss of autonomy and individuation experienced by the patient, leading to a sense of 'helpless dependence'. Selfneglect and non-compliant behaviour allow the patient to gain some control and autonomy. Encouraging personal responsibility for rehabilitation, decision making and planning for the future, involves the patient actively and constructively. Self-hypnosis and relaxation techniques are additional methods of enhancing some degree of mastery (Gallagher et al., 1982).

Dependency and regression enhance transferential relationships with the staff. Kerr and Thompson, 1972, state that the staff unconsciously carry the role of the parent(s). Winnicott, 1971, states to achieve mastery, interaction with a 'good enough mother' is necessary. The provision of firmness and reasonable limit setting assists the patient to gain impulse control (Judd and Burrows, 1986). Understanding the psychological aspects of the patients' rehabilitation fosters the staff's cohesiveness, solidifies morale and enhances empathic and consistent caring, whilst the patient achieves the goal of rehabilitation-the metamorphosis of a dependent 'spinal man' to an independent 'spinal man'. (Bromley, 1984).

\section{Case 1}

Mr J. C., a 21 year old man, was injured in an accidental fall from a building in late 1984. He suffered a C7 fracture, resulting in tetraplegia. One month following injury, he was referred for a psychiatric opinion. The patient had refused antibiotics for a urinary tract infection, was self-administering calcium and vitamin D supplements, which had resulted in the blocking of his urinary catheter, he declined to participate in physiotherapy, was verbally abusive towards the staff and wished to discharge himself. $\mathrm{He}$ was of the opinion that ongoing self-administration of herbs and vitamins would cure his paralysis. Prior to the injury, the patient had been in excellent physical health. His family background was insecure and devoid of adequate parenting. His de facto marital relationship was unstable. Several months before the accident he had committed himself to an eastern religious sect. It was probable that the injury occurred during the conducting of criminal activities. On examination the patient was obviously sad, he was irritable and angry, but did not experience signs or symptoms of a major depressive episode. His profound denial was serving a protective function psychologically, but creating a dangerous medical situation. Management involved facilitating the patient's grief reaction, actively involving the patient in management decisions, intensifying the explanations provided by the staff regarding the various procedures necessary for his care, and clarification of conflicts regarding his 'helpless dependence'. His denial was gradually relinquished and he assumed a more active and responsible role in the management of his cares.

\section{Depressive self-neglect}

Self-neglect was a presenting symptom of a major depressive episode in 9 of the 36 patients. The mean age of these patients was 59.8 years, the mean time elapsed since injury 3.4 years. A variety of non-compliant and self-destructive behaviour presented in this group. Associated with the self-neglect was a pervasive lowering of mood, sleep and appetite disturbance, loss of energy or 
fatigue, poor concentration and indecisiveness, psychomotor retardation or agitation, feelings of worthlessness, self-reproach or inappropriate guilt, and suicidal ideation. When feelings of hopelessness are combined with feelings of helplessness, the risk of suicide is significant. The entire gamut of depressive symptoms is rarely witnessed. Atypical depressive symptomatology such as somatic preoccupation and pain are not uncommon in this group. The lowered affect may be visibly obvious in the facial appearance and behaviourally may be expressed by negative withdrawal. A past or family history of depression increases the risk of post-injury depression. The age of these patients may be an additional risk factor, the young spinal injured patient tending to adjust to disability with less resentment (Kerr and Thompson, 1972). The expectation that 'depression' is 'normal' following spinal injury tends to delay the appropriate diagnosis of these patients. Judd et al., 1986, discusses the clinical differentiation of major depressive episodes and despondency and grief, conservation-withdrawal and regressive reactions.

Treatment with antidepressant medication and supportive psychotherapy generally results in significant improvement of mood, the cessation of selfneglect, and renewed rehabilitation vigour.

\section{Case 2}

Mr A. J., a 63 year old married man, injured in an accidental fall 6 years previously, resulting in T10 paraplegia. Following initial hospitalisation he became almost totally independent in all activities, only requiring minimal help. However, within 2 years of the injury, episodes of intermittent depression were noted, followed by increasing hostility, angry and demanding behaviour, refusal to cooperate with rehabilitation, a refusal to take medications, persistent statements or worthlessness, increasing sacral pains, sleep disturbance, minor weight loss and indecisiveness, and statements threatening suicide. Prior to injury the patient was a physically active, healthy man, with no previous psychiatric history. Management involved supportive psychotherapeutic measures, including explanations and advice regarding the treatment of depressive illness, allowing the introduction of the tricyclic antidepressant drug Imipramine. Significant improvement was noted within 2 months, with a resolution of the depressive symptomatology and the regaining of his previous independent functioning.

\section{Existential self-neglect}

A small number of spinal injured patients, more commonly tetraplegic, decide they would prefer death to a 'spinal-life-style'. Prior to announcing a decision to refuse subsequent active medical treatments, these patients have generally discussed this decision with their families and relatives in a deliberate and nonhostile manner. Fearing disapproval and disappointment by medical and paramedical staff, such a decision may not be openly volunteered, but recognised by a dramatic fall-off of cooperation, self-care and rehabilitation endeavours. On examination, the patient is decisive and persistent in statement, cognitively intact, rational and mentally competent. The affect is neutral, manner calm, behaviour compassionate and the patient is supportive towards others. They are 'actively living until their death', motivated and forceful in their attempts to bring closure to their affairs. Symptoms of a major depressive episode are absent and the pangs of grief resolved. The majority of these patients have lived many 
years post-injury and have adjusted 'well', but of a relatively young age (mean age 38.5 years). Suicidal ideation may be frequently voiced by patients during the immediate post-injury phase (Hohmann, 1975; Pinkerton and Griffin, 1983). These are not the persistent and considered statements of those patients who have gained appropriate independence, and decide not to pursue life.

The management of these patients challenges the medical ethic regarding the preservation of life. Staff and relatives may react with disbelief, anger, sadness, support or rejection. Guilt is easily evoked in carers when the cared opts to reject the carer. However, depriving these patients of psychological autonomy by legal or moral means, adds psychological paralysis to physical paralysis. They are entitled to be 'nursed to death', the aim, as in terminally ill patients, being to assist in the attainment of a comfortable death. As with renal dialysis patients, repeatedly offering the choice of refusal of treatment, may enable these patients to maintain treatment (McKegney and Lange, 1971). Given the right to say 'no', the patient may be enabled to say 'yes' (McCartney 1985-86).

\section{Case 3}

A 39-year-old married woman, with one child, developed transverse myelitis in mid1985. High level tetraplegia resulted, necessitating artificial ventilation. The patient maintained a positive attitude toward life and actively participated in rehabilitation. Despite her profound physical disability, including an intermittent need for assisted ventilation, the patient gained sufficient independence from the hospital to spend periods at home. Eighteen months following her illness, her motivation with respect to rehabilitation was noted to be fading, yet her mood and sociability remained unaffected. The patient declined to inform the staff of her decision to request the cessation of subsequent active medical interventions. She developed an acute septicaemia, and emergency medical interventions were instituted. On recovery, the patient formally communicated this decision. This wish was respected.

\section{Discussion}

This paper indicates that self-neglect is a common complication of spinal injury, and suggests that the literature has not adequately emphasised this potentially avoidable symptom. This paper does not focus on the specific forms of selfneglect, but on self-neglect as a symptom of the underlying psychological, psychiatric or philosophical state. The consequences of self-neglect are costly in physical, emotional and financial terms to the individual, the family, the staff and the care-providing system. Geisler et al., 1983, highlighted the marked decrease in deaths of spinal injured patients due to renal disease since 1945, but the increase of self-determined fatal complications, such as suicide and alcohol abuse. The recognition and management of self-neglect of spinal injured patients is of critical importance.

Recognition of self-neglect is hindered by the patient's denial of, and reluctance to reveal. Carroll et al., 1980 commented that overt non-suicidal self-mutilation is typically followed by a sense of calm, relief and decreased tension, this response thereby further camouflaging the gravity of this symptom to medical and paramedical staff. Recurrent and potentially avoidable hospitalisations create an erosion of morale and a sense of therapeutic impotency in the staff. 
These anxieties are combated by either collusive denial or the hostile rejection of the patient. Increased awareness of this problem may avert this vicious cycle.

Psychiatric assessment of self-neglect of spinal injured patients is advisable in order to establish the appropriate diagnosis and formulate the management plan. The psychological process or psychopathology creating this symptom, determines the treatment modality. Adjustment conflicts expressed as selfneglect was the most prevalent diagnosis in this study. Unrecognised and untreated depressive illness may be causative of self-neglect (Judd and Burrows, 1986), however, more commonly self-neglect is a symptom of an adjustment crisis.

Spinal injury necessitates major adjustment, both physical and psychological. The process of adjustment to spinal injury is reviewed by Judd and Burrows, 1986. The necessary development of a modified identity (Steward 1977-78) is an arduous task involving the gradual integration of the reality of the losses within the person's cognitive, affective and behavioural functioning, and the mastering of physical and psychological dependency. The time for this transformation to occur ranges from 8-12 weeks (Jochheim, 1983), to 2 years (Kerr and Thompson, 1972), to an indefinite period (Bracken and Shepard, 1980). There is, however, consensus in the literature that the disruption of psychological equilibrium caused by the injury, creates emotional distress and a process of mourning. The predominant affect is negative, and a stage of overt anger and/or indifferent withdrawal behaviour is to be expected. Siller, 1969, suggests the prognosis for angry patients to be better, and Kerr and Thompson, 1972 , state that an aggressive and rebellious phase is inevitable. Overt or covert self-neglect is a sign and advertisement of this adjustment turmoil. There may be present a clear attention-seeking motive to self-neglect, a motive deserving of an appropriate response.

Emotional distress and anxiety mobilise ego defences such as denial, repression, regression, rationalisation, projection and displacement, defences designed to be protective, but may be maladaptive if the evolution towards adjustment is delayed or arrested. The behavioural expressions of these defences may be self-neglect, particularly maladaptive denial (Steward, 1977-78). A moratorium early in the adjustment process is described (Steward 1977-78). Delays, detectable by the persistence of behaviour incompatible with physical and psychological independence, can be conceptualised as being the consequence of a conflict within the three variables influencing adjustment to disability, namely the injury, the patient and the staff (and family). Management involves the clarification of this conflict and assisting the patient to gain mastery over their enforced physical and psychological dependency. Parenting skills are staff requirements aiding the patient's transition from a passive to active participant in rehabilitation and their life. The prognosis for the resolution of a self-neglect adjustment crisis is influenced by the factors associated with adjustment-age, sex, pre-injury educational and occupational attainments, pre-injury life satisfaction, the quality of interpersonal relationships, and pre-morbid personality (Judd and Burrows, 1986).

Judd et al., 1986 identified discrete and treatable depressive illness in 10.7\% of consecutive admissions to a spinal injuries unit. Self-punishment, perceived to be deserved and warranted, guilt and worthlessness, may find expression in 
the destruction of the self, undertaken by depressed persons. Palmer, 1985, suggested the role of the Dexamethasone Suppression Test in the diagnosis of depressive illness in spinal injured patients is limited, in view of the altered adrenocortical functioning, thus highlighting the requirement of expert clinical assessment of these patients. The presentation of depression following injury was, in this study, considerably delayed in comparison to the patients of Fullerton et al. (1981) and Judd et al. (1986) for whom depression was recognised within the first few months. This difference may be accounted for by the large geographical catchment area in this study, and the associated inaccessibility to specialist care facilities, and the newly-introduced Consultation Liaison Service enhancing the detection of previously unrecognised depressive illness. Selfinjurious behaviour has been linked to central neurochemical alterations (Dahlin et al., 1985) and acute spinal cord injury may result in catecholamine fluctuations (Alderman et al., 1980) thus theoretically, spinal cord injury, major depressive episodes and self-injurious behaviour may possess a common neurochemical pathway. The efficacy of medications in reducing self-injurious behaviour, not associated with depressive illness, has produced varying results (Schroeder, 1978). Depressive self-neglect has an excellent prognosis and should be an avoidable adversity during the rehabilitation of spinal injured patients.

Diagnostic issues in existential self-neglect are critical. The conservationwithdrawal response is acute and transient, the affect is neutral with no subjective alteration of mood, physical energy is depleted and the patient's interest in the environment diminished (Weiner and Lovitt, 1979). In contrast, patients in this study considered to be existential self-neglecters, portrayed positive affect, their energy levels were normal and their interest in their environment desperately heightened, for having made a decision, they avidly embark upon placing their affairs in order prior to death. There is an absence of depressive symptomatology, the conflicts of adjustment are no longer experienced with emotional pain, and their grief for their disability resolved. It is not a 'passive suicide', but a deliberate, determined and non-punitive decision to be autonomous (McCartney, 1985-86). These patients are sentient, rational and relatively intact human beings, who have decided to let nature take its course (McKegney and Lange, 1971). Gardner et al. (1985) interviewed 21 high tetraplegic patients in order to obtain their retrospective opinions on whether or not, during the acute phase, they were grateful to have been temporarily ventilated. Two were undecided and only one patient wished she had been allowed to die. The will and wish to survive acute spinal cord injury is an issue very different to the one considered in this paper. Existential self-neglect patients have acquired survival, and subsequently decide not to pursue life. Tetraplegia enforces greater physical dependency on others than paraplegia, this being a major factor for the higher proportion of tetraplegics in this group ( 4 of 6 patients). They could have expected a considerable life-span, the mean age being only 38.5 years. The will to survive, mentally competent and tetraplegic, may be determined by pre-injury characteristics incompatible with this disability.

Kas (1980) and Cassell (1977) state that the primary function of medicine is to maintain and assist in the recovery of autonomy. The preservation of life is a subservient goal. Some patients, with the restoration of autonomy, and given the choice to live or die, may choose to live. If deprived of autonomy, the patient 
may opt for self-destruction, utilising methods within their limited physical capabilities i.e. by self-neglect. Dignified death is surely preferable for patient, relatives and staff. Giving up a struggle because one is tired and feels helpless is not identical with self-destruction (Bibring, 1968). Is existential self-neglect a destructive action or a creative solution?

Ohry (1983) described sudden 'silent' sepsis in young chronic traumatic tetraplegic patients, linking this to a similar phenomenon recorded in the elderly. Hayflick (1979) and Goldstein and Harley (1979) postulate the exhaustion of the immunological system in the elderly. The psychiatric equivalent of immunological exhaustion in spinal injured patients may be the phenomenon of existential self-neglect.

\section{References}

Alderman JL, Osterholm JL, D'Amore BR, et al. 1980 Catecholamine alterations attending spinal cord injury: A reanalysis. Neurosurgery 6:412-417.

ARnOtT G 1984 Progress in rehabilitation. Paraplegia. Edited R. Capildeo and A. Maxwell, Macmillan Press, London. p 68.

Bedbrook Sir George, Beer NIE, McLaren RK 1985 Preventive measures in the tertiary care of spinal injured people. Paraplegia 23:69-77.

BIBRING E 1968 The mechanism of depression in the meaning of despair: Edited by Gaylin W. New York Science House, pp. 180.

BRACKEN MB, SHEPARD MJ 1980 Coping and adaptation following acute spinal cord injury: A theoretical analysis. Paraplegia 18:74-85.

Bromley I 1984 Progress in rehabilitation. Paraplegia. Edited R. Capildeo and A Maxwell, Macmillan Press, London. p 58.

CASSELl EJ 1977 The functions of medicine, Hastings Center report: 7, pp.16-19.

CARroll J, Schaffer C, SPEnSLey J, et al. 1980 Family experiences of self-mutilating patients. American fournal of Psychiatry 137:852-853.

DAHLIN PA, VAN BUSKIRK NE, NovotNy RW, et al. 1985 Self-biting with multiple finger amputations following spinal cord injury. Paraplegia 23:306-318.

FRANK RG, KASHANi JH, WoNDERLICH SA, et al. 1985 Depression and adrenal function in spinal cord injury. American fournal of Psychiatry 142:2.252-253.

Fullerton DT, HaRvey RF, KLeIN MH, et al. 1981 Psychiatric disorders in patients with spinal cord injury. Archives of General Psychiatry 38:1369-1371.

Gallagher RM, MCKegney FP, Gladstone T 1982 Psychiatric interventions in spinal cord injury. Psychosomatics 23:11.1153-1167.

GARDNER BP, TheOClEOUS F, WATt JWH, et al. 1985 Ventilation or dignified death for patients with high tetraplegia. British Medical fournal 291:1620-1622.

GEISLER WO, JOUSSE AT, WYNNE-JONES M, et al. 1983 Survival in traumatic spinal cord injury. Paraplegia 21:364-373.

Goldstein S, HaRLey CB 1979 In vitro studies of age associated diseases. Federation Proceedings 38:1862-1867.

GunTHER MS 1971 Psychiatric consultation in a rehabilitation hospital: A regressive hypothesis. Comprehensive Psychiatry 12(6):572-585.

HAYFLICK L 1979 Cell biology of aging. Federation Proceedings 38(5):1847-1850.

HoHMANN GW 1975 Psychological aspects of treatment and rehabilitation of the spinal injured person. Clinical Orthopaedics and Related Research 112:81-88.

HoPKINS G 1971 Patterns of self destruction among the orthopaedically disabled. Rehabilitation Research and Practice Review 3:5-16.

JUDD FK, BURROws GD 1986 Liaison psychiatry in a spinal injuries unit. Paraplegia 24:6-19.

JuDd FK, BurRows GD, BROWN DJ 1986 Depression following acute spinal cord injury. Paraplegia 24:358-363.

JochHeim KA 1983 Psychological aspects of spinal cord injuries. Annals Academy of Medicine, Singapore. 12(3):377-379.

KAS LR 1980 Ethical dilemmas on the care of the ill. I: What is the physician's service? Fournal of the American Medical Association 246:1811-1816.

KERR WG, THOMPSON MA 1972 Acceptance of disability of sudden onset in paraplegia. Paraplegia 10:94-102. 
Malec J, Neimeyer R 1983 Psychological prediction of duration of inpatient spinal cord injury rehabilitation and performance of self-care. Archives of Physical Medicine and Rehabilitation 64:359-363.

MCCARTNEY JR 1985-86 Management of Refusal of Medical Treatment. International fournal of Psychiatry in Medicine 15(1):31-36.

MCKEgNEy FP, LANGE P 1971 The decision to no longer live on chronic hemodialysis. American Fournal of Psychiatry 128:47-54.

NAGLER B 1950 Psychiatric aspects of cord injury. American fournal of Psychiatry 107:49-55.

Nemiah JC 1957 Psychiatrist and Rehabilitation. Archives of Physical Medicine and Rehabilitation 38:143-147.

NYQUIST RH, BoRs E 1967 Mortality and survival in Traumatic Myclopathy during 19 years from 1946-1965. Paraplegia 5:22-48.

OHRY A, Heim M, Rozin R 1983 Peculiar septic responses in traumatic tetraplegic patients. Paraplegia 21:318-321.

PALMER JB 1985 Depression and adrenocortical function in spinal cord injury patients: A review. Archives of Physical Medicine and Rehabilitation 66:253-556.

Petrus J, Balaban AD 1953 Special psychiatric problems of the paraplegic: Report of a case of attempted suicide by a paraplegic. American fournal of Psychiatry 109(9):693-695.

PINKERTON AC, GRIFFIN ML 1983 Rehabilitation outcomes in females with spinal cord injury: A follow-up study. Paraplegia 21:166-175.

SEYMour CT, Comarr AE 1956 Compulsive polysurgery. American fournal of Surgery 91:849851.

SChroeder SR, Schroeder CS, SMith B, et al., 1978 Prevalence on self-injurious behaviours in a large facility for the retarded: A three-year follow-up study. Fournal of Autism and Childhood Schizophrenia 8:261-269.

SILLER J 1969 Psychological situation of the disabled with spinal cord injuries. Rehabilitation Literature 30:290-296.

STEWART TD 1977 Spinal cord injury: A role for the psychiatrist. American fournal of Psychiatry 134(5):538-541.

STEWART TD 1977-78 Coping behaviour and the moratorium following spinal cord injury. Paraplegia 15:338-342.

TrieschmanN RB 1980 Spinal cord injuries: Psychological, social and vocational adjustment. New York, Pergamon Press.

WEINER MF, LOvitT R 1979 Conservation-withdrawal versus depression. General Hospital Psychiatry 4:347-349.

Wilcox N, Stauffer E 1972 Follow-up of 423 consecutive patients admitted to The Spinal Cord Centre Rancho Los Amigos Hospital, 1st January to 31st December, 1967. Paraplegia 10:115122.

WINNICOTt DW 1971 Playing and reality. New York. Basic Books. 